Article

\title{
Engendering a Sense of Belonging to Support Student Well-Being during COVID-19: A Focus on Sustainable Development Goals 3 and 4
}

\author{
Sylvan Blignaut ${ }^{1, *}$, Gary Pheiffer ${ }^{2}$, Lesley Le Grange ${ }^{3}{ }^{\circledR}$, Suriamurthee Maistry ${ }^{4}$, Labby Ramrathan ${ }^{5}$, \\ Shan Simmonds ${ }^{6}$ and Anja Visser ${ }^{6, *}$ \\ 1 Department of Postgraduate Studies, Faculty of Education, Nelson Mandela University, \\ Gqeberha 6019, South Africa \\ 2 Hertfordshire Business School, University of Hertfordshire, Hatfield AL10 9EU, UK; g.pheiffer@herts.ac.uk \\ 3 Department of Curriculum Studies, Faculty of Education, Stellenbosch University, \\ Stellenbosch 7600, South Africa; llg@sun.ac.za \\ 4 Social Sciences Education, School of Education, University of KwaZulu-Natal, Durban 4041, South Africa; \\ maistrys@ukzn.ac.za \\ 5 Teacher Development Studies, School of Education, Education Studies Cluster, University of KwaZulu-Natal, \\ Durban 4041, South Africa; ramrathanp@ukzn.ac.za \\ 6 Education and Human Rights in Diversity Research, Faculty of Education, North-West University, \\ Potchefstroom 2520, South Africa; shan.simmonds@nwu.ac.za \\ * Correspondence: sylvan.blignaut@mandela.ac.za (S.B.); anja.visser@nwu.ac.za (A.V.)
}

\section{check for} updates

Citation: Blignaut, S.; Pheiffer, G.; Le Grange, L.; Maistry, S.; Ramrathan, L.; Simmonds, S.; Visser, A. Engendering a Sense of Belonging to Support Student Well-Being during COVID-19: A Focus on Sustainable Development Goals 3 and 4. Sustainability 2021, 13, 12944. https://doi.org/10.3390/ su132312944

Academic Editor: Manuel Pacheco-Romero

Received: 20 October 2021 Accepted: 17 November 2021 Published: 23 November 2021

Publisher's Note: MDPI stays neutral with regard to jurisdictional claims in published maps and institutional affiliations.

Copyright: (c) 2021 by the authors. Licensee MDPI, Basel, Switzerland. This article is an open access article distributed under the terms and conditions of the Creative Commons Attribution (CC BY) license (https:/ / creativecommons.org/licenses/by/ $4.0 /)$.
Abstract: The COVID-19 pandemic has exposed a plethora of inequalities in South Africa. These inequalities have had a direct impact on the 2030 Agenda for Sustainable Development Goals (SDGs). SDG 3 (good health and well-being) and SDG 4 (quality education) were the focus of this article. This article investigated how students enrolled at a South African residential university perceived the impact of the COVID-19 pandemic on their well-being, their success in completing their studies and their future career prospects. A quantitative survey research design was followed. Data were collected by means of a questionnaire from 537 students in a South African university. Statistical Package for Social Sciences software version 27 was used to analyze the data. The results indicated direct influences on student well-being from concerns that arose from COVID-19 about future job concerns, degree completion, social support and belonging. The relationship between concerns about degree completion was moderated by a sense of belonging (social identification) but not by social support. The study has significant implications for how higher education institution governors and academics might consider reconceptualizing notions of student support, beyond the narrow, technical and basic curriculum support for degree completion, towards the affective and social as it relates to creating conditions for students to identify with and experience a profound sense of belonging.

Keywords: belonging; COVID-19; quality education; South Africa; university students; well-being

\section{Introduction}

In 2015, the 2030 Agenda for Sustainable Development was adopted by the United Nations. It provided a framework for advancing future peace and prosperity [1]. The sustainable development goals (SDGs) were developed to guide this agenda. The 17 SDGs are interrelated, but in this article, we foreground two: SDG 3 (good health and well-being) and SDG 4 (quality education). SDG 3 concerns ensuring healthy lives and promoting well-being for all at all ages. SDG 4 relates to ensuring inclusive and equitable quality education and the promotion of life-long learning opportunities for all.

What the COVID-19 pandemic has laid bare is that the achievement of SDGs 3 and 4 by 2030 might be wishful thinking. The pandemic found health care systems across the globe wanting due to governments' lack of spending on healthcare. Moreover, studies that 
have focused on vulnerable populations show huge disparities in resource allocation and that this perpetuates poverty and segregation [2]. Studies in the USA show that Blacks have been disproportionately affected by the harmful effects of the COVID-19 pandemic [2,3]. Disparate health outcomes are caused by socio-economic and environmental factors including poor nutrition and living conditions. Such disparate COVID-19 outcomes are likely to be witnessed in all unequal societies and where structural health inequities exist, and South Africa is no exception. Inequities in access to healthcare in South Africa is well documented $[4,5]$. There is a close relationship between human health (particularly mental health) and well-being, and studies show that the COVID-19 pandemic has impacted adversely on mental health and well-being, including that of university students $[6,7]$. High levels of depression have been experienced by students because of difficulties with focusing on academic work [6], and a lack of physical exercise during lockdown periods also impacts negatively on well-being [8]. The pandemic has also adversely affected women because it has increased the care burden of women [9], and jobs dominated by women such as in the medical profession and education (particularly early childhood development) placed women in vulnerable positions [10]. Female students might therefore view future career prospects with less certainty. Isolation due to COVID-19 restrictions, isolation from the physical university and its inhabitants as well as the transition to a different mode of learning could impact on students' sense of belonging. Belonging involves the process by which one develops a sense of identifying with one's social, relational and material environments [11].

As mentioned, SDG 4 focuses on quality education and opportunities for lifelong learning. The COVID-19 pandemic resulted in the closure of schools and universities during lockdown periods, and the migration from face-to-face teaching and learning in residential universities to emergency remote teaching, learning and assessment (ERTLA). The pivot to ERTLA laid bare how deep the digital divide is in South Africa [12]. In South Africa, the infrastructure provided by a residential university goes some way to levelling the playing fields with respect to access to devices and connectivity. However, when students had to return home during lockdown periods, the chasm between poor and rich students became visible, not just in terms of access to devices and connectivity but also because of disparate living and, therefore, learning conditions. Poor living and learning conditions and a lack of access to devices and connectivity impact on a student's ability to receive quality education. When the learning environment is online, a digital divide exacerbates education inequities. What becomes cardinal is the support students receive from the university to enable them to complete their studies. A recent study showed that support given by university lecturers and administrative staff has a mediating role in the relationship between the perceived influence of COVID-19 on degree completion, job prospects and levels of student well-being [13]. The mentioned study was an online survey administered to undergraduate students from France, Germany, Russia and the UK. It would therefore be informative to establish whether data generated from the same online survey instruments produce corroborating results when administered to undergraduates at a university in a Global South country, namely, South Africa.

COVID-19, and the subsequent stringent lockdown measures, meant that all traditional face-to-face instruction was not possible. For students, this created conditions of unprecedented isolation and physical separation. The extent to which student well-being was likely to be affected became a cause for concern. There was much uncertainty as to how to mitigate the effects of isolation, especially given that an overwhelming body of knowledge indicates that learning is essentially a social process. The focus of this article, thus, is on how students enrolled at a South African residential university perceived the impact of the COVID-19 pandemic on their well-being, their success in completing their studies and their future career prospects. The article is divided into the following sections: theoretical framework, research methods, results, findings and discussion and conclusion. 


\section{Previous Research}

\subsection{The Perceived Impact of COVID-19: Student Well-Being and Quality Education}

The scholarship on general human well-being is characterised by a cacophony of theories ranging from pleasure-seeking (self-indulgent), desire satisfaction theories (hedonia) to happiness seeking theories (eudaimonia) to objective-list theories [14]. While research on student well-being has also produced much variation, in recent years, there has been some degree of convergence as to what might constitute student well-being in higher education. Even most recently, the COVID-19 pandemic has triggered a proliferation of international studies on student well-being (see for example [15]).

A recent study in the United States [16] reveals that unprecedented historical events such as the COVID-19 pandemic, the global legacy of institutionalised racism, have had, as macro mediating factors, a telling effect on student well-being at the meso (university) level as well as at the micro (personal) level. On a micro (personal) level, a study [17] across 62 countries, sampling 30,383 students investigated the effects of the COVID-19 pandemic. Although a number of key findings emerged, students were mainly concerned about their current studies, future professional careers and experienced overall boredom, anxiety and frustration [17]. The student participants from Africa (Ghana, Nigeria and Egypt) were particularly concerned about their future job prospects due to economic turmoil (55.7\%); their current financial position to fund their studies due to loss of temporary work or permanent loss of employment of those funding their studies (50.8\%); and their inability to travel abroad as part of student mobility, international students returning to family and seeking employment beyond national borders (30.1\%). These student responses from Africa corroborate with South African students' experiences during the first wave of the pandemic. The Human Sciences Research Council (HSRC) and Higher Health Centre surveyed more than 13,000 students in the Post School Education and Training (PSET) Sector to determine the impact of the COVID-19 pandemic on youth in South Africa [18]. Several themes were investigated ranging from substance use, exposure to violence, financial support, student well-being and impact on learning. The main challenges experienced by students during lockdown were psychological distress $(65 \%)$, loss of study time $(57.9 \%)$, not having enough money for essential personal items for studying (55.8\%), loss of social contact $(42.2 \%)$ and not having enough money for food $(40.1 \%)$, and $25.4 \%$ of students said they experienced physical violence more during lockdown than before [19]. For government, these findings have necessitated greater intuitional support, increased communication as well as health and well-being strategies. In terms of the latter, governments urged that pro-active health and well-being programmes be developed and implemented across all institutions nationally through initiatives such as core curricula that take heed of psychosocial dimensions toward maintaining and promoting health and well-being as well as coping strategies through multi-disciplinary support mechanisms for acute situational counselling and debriefing sessions [18]. For Soudien [20], this requires a new alignment of affordances, mechanisms, institutions and support personnel.

We therefore propose the following hypotheses to examine whether the COVID-19 pandemic could have a negative effect on students' well-being because studies have shown that students may experience more stress concerning uncertainties associated with their academic success and future job prospects [18]:

Hypotheses 1a (H1a). Student perceived concerns of the impact of the COVID-19 pandemic on degree attainment predicts levels of student well-being negatively.

Hypotheses $\mathbf{1 b} \mathbf{( H 1 b ) . ~ S t u d e n t ~ p e r c e i v e d ~ c o n c e r n s ~ o f ~ t h e ~ i m p a c t ~ o f ~ t h e ~ C O V I D - 1 9 ~ p a n d e m i c ~ o n ~}$ future job prospects predicts levels of student well-being negatively.

\subsection{The Perceived Impact of Social Support}

In the South African higher education context, which is characterised by a large proportion of first-generation students, it is no wonder that government is stressing the need for a considered approach in addressing both socio-cultural and economic factors that 
students are experiencing [21]. In terms of the socio-cultural, it is without contention that social isolation brought about by COVID-19 has exacerbated mental health concerns of all students. This is fuelled by neoliberal accommodationism, that is, the individualisation of responsibility for well-being [22], an ideological tenet that needs to be disrupted. An inclusive partnership modality [23] that actively solicits student perspectives might enable empowering initiatives to mitigate the conditions that diminish student well-being [22] By seeking out situation-specific strategies to reduce student stress and to help students develop competences to respond effectively to stress, they can better navigate the new demands facing degree completion. On par with the socio-cultural factors, the economic ramifications of the pandemic have arguably been just as unsettling [24]. Diminished employment prospects that COVID-19 presents in a South African economy plagued by poor labour absorption rates even before the pandemic [25], together with fiscal austerity [26], as it relates to student funding are perennial challenges that students experience. This paints a grim picture of a lived reality that is likely to compromise the quality of student well-being and aspirations for degree completion as the financial situation has stripped many students of the resources that they need to gain access to online learning, pay tuition fees and secure funding to see their studies to fruition.

In the fluctuation "new normal" of COVID-19 and post-COVID-19 fluctuating, Plakhotnik, et al. [13] argue that social support can be a significant moderator to capacitate students to cope with the socio-cultural and economic factors that they experience if universities prioritise support for students' studies. This includes awareness of how students' emotional responses change vis-à-vis the crisis and ensuring that student support is made visible and accessible [13]. This resonates with research conducted with students and their expectations for how universities can enhance their mental well-being [23]. In this research, students revealed that social support has various dimensions ranging from curricular activities, social life, student services and physical spaces. Students regarded the attributes of their lecturers as having a direct influence on how the support provided was received. Lecturers with communication skills that were approachable and empathic proved to lower the negative effects that they are experiencing [23]. In addition, students revealed that support services are only useful if institutions create an increased awareness and promote the use of these services (in the form of, for example, counselling, academic skills and student advice) and if institutions are adequately resourced to meet students demands of these services through improved availability, range and the overall quality of the services [23]. For Ye, et al. [27], COVID-19-related stressful experiences are not only mediated through social support, but resilience and adaptive coping strategies also prove significant to minimise stress disorders among students.

Therefore, students do need university support to increase their well-being. We thus propose the following hypotheses:

Hypotheses 2a (H2a). Perceived social support will moderate the relationship between student perceived concerns of the impact of COVID-19 on degree completion and levels of student well-being.

Hypotheses $\mathbf{2 b} \mathbf{( H 2 b ) . ~ P e r c e i v e d ~ s o c i a l ~ s u p p o r t ~ w i l l ~ m o d e r a t e ~ t h e ~ r e l a t i o n s h i p ~ b e t w e e n ~ s t u d e n t ~}$ perceived concerns of the impact of COVID-19 on future job prospects and levels of student well-being.

\subsection{The Moderating Role of Belonging (Identification)}

A supportive and enabling environment on campus has been proven to ensure student well-being [28,29]. Student well-being could be moderated through a sense of identification such as belonging, positive relationships with others, autonomy and competencies [23]. Academics, as those who work most directly with students, can play a central role in raising meta-awareness of student well-being [30] through enabling pedagogies and a philosophy/pedagogy of care [31] that should ideally be constitutive of a comprehensive university-wide strategy to enhance student well-being [32]. It thus entails an integrated, embedded approach involving partnerships between the university's mental health professionals and academics as they forge a curriculum that addresses student 
mental well-being [33]. For improved student well-being, an inclusive and humanising pedagogy is needed [34]. This correlates with a study conducted by Eloff and Graham [35] who found that the deterioration in the mental health and well-being of South African students necessitates proactive initiatives that develop student self-efficacy, feelings of affinity, affiliation and connectedness. For Soudien [20] (p. 65), this can become possible if academic institutions take heed of "the politics of learning" and not only be consumed by dealing with the COVID-19 pandemic through restabilising steps because stabilisation is a return to the conditions of dominance. The politics of learning challenges our longstanding ills of thinking we have a homogenous student body who we can teach using inflexible and one-size-fits-all pedagogies. Instead, it forces us to confront the challenges that arise now that teaching is no longer within traditional parameters and reveals different dimensions of learning as multiple modalities that shape our students" "bodies, brains and social circumstances" as "their epigenetic holism, impact how each of them is learning" [36] (p. 258). This speaks directly to ideas on belonging and the attachment students may have as a source of security and support.

In their seminal work on learning in a community of practice, Lave and Wenger [37] contend that a key aspect of community of practice membership is the notion of belonging. Affinity, connection and inclusion are crucial elements that might assist members of a group to identify with the group and to develop own identities within groups through mutual engagement, sharing a common learning enterprise and by employing a shared repertoire for group engagement [38]. The uncertainty created by COVID-19 and social distancing in particular triggers what Godinic, Obrenovic and Khudaykulov [39] describe as social identity disturbance, a rupturing of a sense of belonging that is likely to affect the mental health of people. In recent work, Hogg [40] contends that social identity theory emphasises the importance of individual self-conception as individuals interact within groups. James and Theriault [41], in their assessment of contemporary research on adult education and learning during the COVID-19 pandemic, argue that learning is likely to be enhanced in groups where members feel a strong sense of belonging, an intimate affiliation that affirms a sense of self. This is corroborated by Mooney and Becker's [42] study, which confirms that the sudden shift to online learning affected students' sense of belonging and that more attention be directed at how institutions and pedagogues might actively work towards facilitating the formation of inclusive learning communities. Student perceptions of a sense of belonging thus warrants closer investigation, and therefore, we propose the following hypotheses:

Hypotheses 3a (H3a). Belonging (Identification) will moderate the relationship between student perceived concerns of the impact of COVID-19 on degree completion and levels of student well-being.

Hypotheses $\mathbf{3 b} \mathbf{\mathbf { b }} \mathbf{H} \mathbf{b})$. Belonging (Identification) will moderate the relationship between student perceived concerns of the impact of COVID-19 on future job prospects and levels of student well-being.

\section{Method}

\subsection{Study Participants and Procedure}

This study forms part of a larger international study exploring the influence of the COVID-19 pandemic on student well-being, conducted in eight countries [13]. This study reports on data collected from a university in South Africa. Ethical clearance was obtained from the Research Ethics Committee of Nelson Mandela University (NMU) (H20-EDUERE-024), and the study conformed to these and general ethical procedures. Therefore, the study design was a case study of one South African institution; however, the institution has students from several provinces in this country. Students completed the survey voluntarily and anonymously. All students at NMU were recruited by emailing a link to the survey via the university email system using the Qualtrics XM software and closed on 10 June 2020. The survey questionnaire was available online for a period of three weeks. In total, 2100 students responded to the questionnaire, and 537 were available for analysis when all participants with missing data were removed. The indications were that the 
questionnaire was too lengthy, and future work might benefit from having shorter surveys and the use of one item scales might be useful.

Table 1 provides the demographics and contextual information of the participants. From the students in the sample, the mean age was 23 years old. The standard deviation for age was 5.178. The youngest participant was 17 years and the oldest participant was 52 . At the time of responding to the survey, $78.6 \%$ of students lived at home and $0.7 \%$ reported being on campus. The participants differed in their study years with $88 \%$ undergraduate students and $12 \%$ postgraduate students.

Table 1. Demographics and contextual information of participants.

\begin{tabular}{|c|c|c|c|}
\hline Variables & & Frequency & Percent \\
\hline \multirow{5}{*}{ Residing } & Home & 422 & 78.6 \\
\hline & Still on campus & 4 & 0.7 \\
\hline & With friends & 8 & 1.5 \\
\hline & With family & 85 & 15.8 \\
\hline & Other & 18 & 3.4 \\
\hline \multirow{3}{*}{$\begin{array}{l}\text { Study } \\
\text { mode }\end{array}$} & Full time & 499 & 92.9 \\
\hline & Part time & 38 & 7.1 \\
\hline & Other & 0 & 0 \\
\hline \multirow{8}{*}{$\begin{array}{l}\text { Study } \\
\text { year }\end{array}$} & Undergraduate year 1 & 169 & 31.5 \\
\hline & Undergraduate year 2 & 151 & 28.1 \\
\hline & $\begin{array}{l}\text { Undergraduate year } 3 \\
\text { (Placement/Study Abroad) }\end{array}$ & 28 & 5.2 \\
\hline & Undergraduate year 3 (Final year) & 86 & 16 \\
\hline & Undergraduate year 4 (Final year) & 39 & 7.3 \\
\hline & Postgraduate year 1 & 47 & 8.8 \\
\hline & Postgraduate year 2 & 9 & 1.7 \\
\hline & Postgraduate other & 8 & 1.5 \\
\hline \multirow{7}{*}{$\begin{array}{l}\text { Study } \\
\text { area }\end{array}$} & Astronomy, physics, maths & 95 & 17.7 \\
\hline & Business & 179 & 33.3 \\
\hline & Computer Science & 58 & 10.8 \\
\hline & Education & 74 & 13.8 \\
\hline & Health and Social Work & 64 & 11.9 \\
\hline & Humanities & 8 & 1.5 \\
\hline & Live and Medical Sciences & 59 & 11 \\
\hline
\end{tabular}

The majority of participants (92.6\%) reported that they followed lockdown regulations with $0.4 \%$ stating that they were not following or ignoring guidance. Only $6.5 \%(\mathrm{~N}-35)$ of the participants reported that they never have been worried by COVID-19, where other students were worried to some extent about COVID-19. In relation to their online studies, $15.1 \%$ of the participants rated online studies as not effective at all, and other participants rated online learning to be effective to some degree. Online studies were not stressful at all for $5.6 \%$ of the participants, moderate to mild stress was reported by $40.4 \%$ of participants and $47 \%$ of the participants reported that they were very or extremely stressed. The majority of participants perceived some negative impact on their studies $(74.4 \%)$, and $15.9 \%$ stated that they perceived no impact on their studies, while $9.7 \%$ reported a positive impact on their studies.

\subsection{Measures}

The survey consisted of 27 items and included demographic details such as sex, age, nationality, place of residence, study mode and year of study. Following Plakhotnik, et al. [13], the succeeding four scales were included as the variables of the study. All the items used a 5-point Likert scale.

Overall support: This was measured by an adaption of the social support scale developed by Pierce, et al. [43]. Students rated the extent to which they had received 
support from university staff members, as well as friends and family. Students' ratings were measured on a 5-point Likert scale (e.g., "Please rate these as they apply to your current experience: I get support that I need from the following: My lecturers"). A good internal consistency of $\alpha=0.75$ was achieved.

General positive well-being: The study explored the overall effects that predictors had on student well-being, and these were measured using a Likert scale. General positive well-being was measured by five items derived from the World Health Organization [44]. This scale was used to measure student mood-based affect and responses ranged from "strongly disagree" to "strongly agree", etc. A sample item is "I have felt cheerful and in good spirits and I have felt calm and relaxed". A satisfactory internal consistency of $\alpha=0.74$ ) was found.

Belonging (Identification): The single item scale developed by Postmes, Haslam and Jans [45] was used to measure identification. It was adapted to capture the variable of belonging. The single item was developed into a three-item scale and asked, "As a result of the crisis: I still feel part of the University, I still feel part of my friendship group, I still feel like a student." This measured an overall sense of belonging $(\alpha=0.74)$.

Student Concerns: This scale was devised by Plakhotnik, et al. [13] to assess participants' concerns about the impact of COVID-19. Seven items were used to capture student concerns and were rated on a five-point Likert scale ranging from "not at all stressed" to "extremely concerned". These seven items made up two sub scales: concerns for degree completion and concerns for future job prospects.

Degree completion concerns: the perceived effect of COVID-19 on students' capacity to complete their degrees and meet academic demands. The subscale included the following items: "my exams and assessments", "my ability to complete my course", "my final degree/course qualification grade" and "my grades". This subscale produced a very good internal consistency, which measured $\alpha=0.89$. Concerns for future job prospects measured the perceived effect of COVID-19 on student ability to be gainfully employed upon graduation. The subscale included the following three items: "my employability", "the wider economy" and "job prospects". This subscale also produced a good internal consistency $(\alpha=0.86)$.

\subsection{Statistical Analysis of Data}

Version 27 of the Statistical Package for Social Sciences (SPSS) was used to analyse the data [46]. Means, standard deviations and correlations were generated using descriptive statistical analysis (see Table 2). Multiple regression was used to test the hypotheses (H1a and H1b) that COVID-19 concerns about degree completion and future job prospects negatively impacted on general well-being. Multiple regression analysis using Hayes' [47] PROCESS macro model 2, which utilizes bootstrapping, was used to test if the two student concerns significantly predicted participants' ratings of well-being and the potential moderating role of social support and belonging. Exploring these interactions may assist in understanding the conditions under which student COVID-19 concerns and ratings of well-being may differ, so as to help understand what may influence this relationship to be stronger, weaker or possibly reversed. To establish the significance of this suggested relationship, zero is explored to see if it lies between the values of lower level of confidence interval (LLCI) or upper level of confidence interval (ULCI); if zero is not within these confidence intervals, it denotes a significant moderating effect [47]. The results of the regression are provided in Tables 3 and 4 . 
Table 2. Descriptive statistics and correlations of key study variables.

\begin{tabular}{lcccccc}
\hline Variables & $\mathbf{M}$ & SD & $\mathbf{1}$ & $\mathbf{2}$ & $\mathbf{3}$ & $\mathbf{4}$ \\
\hline 1. Support & 3.66 & 1.01 & & & & \\
\hline 2. Belonging & 3.40 & 0.92 & $0.509^{* *}$ & & & \\
\hline 3. General WB & 2.38 & 1.06 & 0.473 & $0.485^{* *}$ & & \\
\hline $\begin{array}{l}\text { 4. Concerns for } \\
\text { degree completion }\end{array}$ & 3.90 & 1.04 & $-0.308^{* *}$ & $-0.366^{* *}$ & $-0.531^{* *}$ & \\
\hline $\begin{array}{l}\text { 5. Concerns for } \\
\text { future job prospects }\end{array}$ & 3.82 & 1.05 & $-0.200^{* *}$ & $-0.278^{* *}$ & $-0.316^{* *}$ & $0.695^{* *}$
\end{tabular}

Note: $\mathrm{M}=$ Mean; SD = Standard Deviation; N = 527; WB-well-being; ${ }^{* *} p<0.01$, two-tailed. The numbers in the title row correspond to the numbers of variables in the first column.

\section{Results}

The results section is divided into three subsections. The first subsection deals with hypothesis H1a and H1b. The second subsection deals with hypotheses H1a, H2a and H3a. The third subsection deals with hypotheses H1b, H2b and H3b.

\subsection{Student Perceived COVID-19 Concerns on Degree Attainment and Future Job Prospects}

The descriptive statistics and properties of the key scales and variables are shown in Table 2. The variables were measured on a Likert scale of one to five, where five is a high score and one is a low score on the variables in Table 2. Significant negative correlations were found between COVID-19 concerns about degree attainment and future-term job prospects and student well-being ( $\mathrm{H} 1 \mathrm{a}$ and $\mathrm{H} 1 \mathrm{~b})$. Moderators, social support and belonging were all significantly positively associated with student well-being.

\subsection{Concerns for Degree Completion and Student Well-Being}

In Table 3, the results of the regression analysis using PROCESS with concern for degree completion as the predictor variable and concern for future job prospects as a covariate indicated a collective significant effect between the students' concern for degree completion, for future job prospects and student well-being. The overall model explained $43 \%$ of the variance $(\mathrm{R} 2=0.4349, \mathrm{~F}(2=6,530)=67.9812, p=0.00)$.

Table 3. Multiple regression moderation analysis for degree completion.

\begin{tabular}{|c|c|c|c|c|c|c|}
\hline \multicolumn{7}{|c|}{ Outcome Variable: Well-Being } \\
\hline Variables & Coefficient & se & $\mathbf{t}$ & $p$ & LLCI & ULCI \\
\hline Constant & -0.0538 & 0.0355 & -1.5158 & 0.1302 & -0.1234 & 0.0159 \\
\hline $\begin{array}{l}\text { Concerns for degree } \\
\text { completion }\end{array}$ & -0.4242 & 0.0498 & -8.5095 & 0.0000 & -0.5221 & -0.3262 \\
\hline Support & 0.2384 & 0.0387 & 6.1551 & 0.0000 & 0.1623 & 0.3145 \\
\hline $\begin{array}{l}\text { Concern for degree } \\
\text { completion } X \text { support }\end{array}$ & 0.0450 & 0.0371 & 1.2148 & 0.2250 & -0.0278 & 0.1178 \\
\hline Belonging & 0.2463 & 0.0398 & 6.1889 & 0.0000 & 0.1681 & 0.3245 \\
\hline $\begin{array}{l}\text { Concern for degree } \\
\text { completion } \mathrm{X} \\
\text { belonging }\end{array}$ & -0.1043 & 0.0419 & -2.4878 & 0.0132 & -0.1866 & -0.0219 \\
\hline $\begin{array}{l}\text { Concerns for future } \\
\text { job prospects }\end{array}$ & 0.1107 & 0.0466 & 2.3775 & 0.0178 & 0.0192 & 0.2022 \\
\hline
\end{tabular}

The individual predictors for student well-being indicated that concerns for degree completion $(\mathrm{t}=-8.5095, p=0.000)$, concerns for future job prospects $(\mathrm{t}=-2.3775$, $p=0.0178)$, belonging $(t=6.1889, p=0.000)$ and social support $(t=6.1551, p=0.000)$ were 
significant predictors. The regression analysis did not support hypothesis $\mathrm{H} 2 \mathrm{a}$ that social support was a moderator on the relationship between student perceived concerns of the impact of COVID-19 on degree completion and levels of student well-being $(t=1.21, b=0450$, $p=0.2250$, CI: $-0.0278 ; 0.1178$ ). The lower limit confidence interval (LLCI) is -0.0278 , and the upper limit confidence interval (ULCI) is 0.1178 , and because zero is inside the confidence intervals, the interaction does not have a significant effect.

Hypothesis $3 a$ that perceived belonging moderates, the relationship between student perceived concerns of the impact of COVID-19 on degree completion and student wellbeing was supported $(\mathrm{t}=-2.4878 ; \mathrm{b}=-0.1043, p=0.0132, \mathrm{CI}:-0.1866 ;-0.0219)$. The lower limit confidence interval (LLCI) is -0.1866 , and the upper limit confidence interval (ULCI) is -0.0219 , and because zero is outside the confidence intervals, it is a significant effect.

Overall, as seen in Table 3, the analysis of the moderating role of social support and belonging found a significant interaction with belonging but not an interaction (moderation) with social support. It was also found that for the undergraduate students, there were no significant differences between the year of study for concerns about degree completion.

\subsection{Concerns for Future Job Prospects and Well Being}

The results in Table 4 indicate that there was a significant difference $(t(471)=-2.09$, $p=0.037$ ) between undergraduate final year students and those not in their final year for concerns for future job prospects $(M=4.00)$ and the other years of study $(M=3.77)$. The results of the moderation analysis are given in Table 4 with concern for future job prospects entered as independent variable with concerns for degree completion as covariate and well-being as the outcome variable. Belonging and social support were the potential interaction (moderator) variables in this model.

Table 4. Multiple regression moderation analysis for future job prospects.

\begin{tabular}{lcccccc}
\hline \multicolumn{7}{c}{ Outcome Variable: Well-Being } \\
\hline \multicolumn{1}{c}{ Variables } & Coefficient & se & $\mathbf{t}$ & $\boldsymbol{p}$ & LLCI & ULCI \\
\hline Constant & -0.0409 & 0.0343 & -1.1916 & 0.2339 & -0.1083 & 0.0265 \\
\hline $\begin{array}{l}\text { Concern for future job } \\
\text { prospects }\end{array}$ & 0.1180 & 0.0473 & 2.4948 & 0.0129 & 0.0251 & 0.2110 \\
\hline $\begin{array}{l}\text { Support } \\
\text { Concern for future job }\end{array}$ & 0.2427 & 0.0389 & 6.2374 & 0.0000 & 0.1663 & 0.3192 \\
\hline $\begin{array}{l}\text { prospects X support } \\
\text { Belong }\end{array}$ & 0.0202 & 0.0402 & 0.5015 & 0.6162 & -0.0589 & 0.0992 \\
\hline $\begin{array}{l}\text { Concern for future job } \\
\text { prospects X belong }\end{array}$ & -0.0556 & 0.0413 & -1.3458 & 0.1789 & -0.1368 & 0.0256 \\
\hline $\begin{array}{l}\text { Concern for degree } \\
\text { completion }\end{array}$ & -0.4454 & 0.0483 & -9.2204 & 0.0000 & -0.5404 & -0.3505 \\
\hline
\end{tabular}

The individual predictors for the impact on well-being were examined and indicated that concerns for future job prospects $(\mathrm{t}=-2.4948, p=0.0129)$, concerns for degree completion $(\mathrm{t}=-9.2204, p=0.0000)$, model social support $(\mathrm{t}=6.2374, p=0.0000)$ and belonging $(\mathrm{t}=5.9185, p=0.0000)$ were significant predictors in the model.

The results of the moderation regression analysis did not support hypotheses H3a and H3b that social support (CI: $-0.0589 ; 0.0992)$ and belonging (CI: $-0.1368 ; 0.0256)$ were a moderator on the relationship between student perceived concerns of the impact of COVID-19 on future job prospects and levels of student well-being. As the lower limit confidence interval (LLCI) and the upper limit confidence interval (ULCI) are both at zero, the interactions do not have a significant effect. 


\subsection{Summary of Main Findings}

Student perceived concerns of the impact of COVID-19 on degree attainment/realisation and future job prospects negatively predicted levels of student well-being (H1a and $\mathrm{H} 1 \mathrm{~b}$ ). The moderators, namely, social support and belonging were positively associated with levels of student well-being. H2a was not supported and therefore social support did not moderate the relationship between student perceived concerns of the impact of COVID-19 on degree completion and levels of student well-being. $\mathrm{H} 2 \mathrm{~b}$ and $\mathrm{H} 3 \mathrm{~b}$ were also not supported and therefore social support and belonging were not a moderator between student perceived concerns of the impact of COVID-19 on future job prospects and levels of student well-being. However, H3a was supported through regression analysis, in other words belonging moderated the relationship between student perceived concerns of the impact of COVID-19 on degree completion and levels of student well-being.

The results indicate direct influences on student well-being from concerns that arose from COVID-19 about future job concerns, degree completion, social support and belonging. The relationship between concerns about degree completion was moderated by a sense of belonging (social identification) but not by social support. Neither of the two moderators had an interaction with a concern for future job prospects and well-being. So, the relationship between COVID-19 concerns and well-being is stronger among those students with a lower (vs. higher) level of belonging.

\section{Discussion}

The findings of this study corroborate with that of Plakhotnik, et al. [13] that students perceive support they received from lecturers and university administrative staff during the pandemic positively impacts on levels of wellbeing, as well as their prospects of completing their degree and securing jobs. However, what the study currently shows is that belonging has an interaction effect in the relationship between COVID-19 concerns and student well-being with a direct relationship with social support. In other words, although support given to students is important, increasing support to students will be enhanced with students' having a strong sense of belonging. We shall therefore focus our discussion on belonging. Yuval-Davis [48] argues that it is useful to distinguish between three major analytical dimensions in which belonging could be framed: social locations; people's identifications and emotional attachments to diverse groupings and collectives; as well as ethical and political value systems.

Concerning the first dimension, during the pandemic we saw students being relocated from the residential university to their homes. At the time of data collection, only $0.7 \%$ of students at the university remained on campus. Although students may have emotional and other attachments to their homes (places where they live), these might not be associated with studying/learning, so relocating students to their homes during South Africa's first hard lockdown could have impacted negatively on their sense of belonging. The physical infrastructure that the residential university provides, including residences, lecture venues, learning commons, sport facilities, etc., might all impact on students' sense of belonging. Concerning the second dimension, students in a residential university belong to different groupings, including sports clubs, cultural and recreational societies, leadership groups, student political groups, etc., to which they have attachments, which foster a sense of belonging. Engagement in the groupings mentioned became eroded during the pandemic and therefore a loss of belonging might have been felt. However, belonging does not have fixity and is always a dynamic process [48], and during the pandemic, a sense of belonging would likely have been fostered among students through social media groups. It is important for universities to recognize that belonging is a dynamic process and that various online platforms could be used to enhance students' sense of belonging during the pandemic and beyond. Concerning the third dimension, there is an ethical value that could be invoked and cultivated to enhance students' sense of belonging, that is, the cultural value of ubuntu. Ubuntu is derived from proverbial expressions in several languages in Africa south of the Sahara but also has value beyond Africa and resonates with many other 
concepts in the indigenous world. It is not only a linguistic concept and a cultural practice but has a normative connotation embodying how we ought to relate to the other-what our ethical obligation is towards the other. It promises an alternative to Decartes cogito, "I think therefore I am", which captures the dualism that characterizes much of Western thought and explains the privileging of epistemology in Western education. Ubuntu—_Because we are, therefore I am" does not separate ontology, epistemology and axiology-the three are imbricated in one another. In short, it means humanness, that I am only a human being because of other human beings. When I harm others, I am also harming myself, when I love others, then I am loved in return.

Within the South African context, student dropout, throughput and graduation rates were and still are a major concern [49], especially within a transforming and inclusive higher education system set against White Paper 3: A Programme for Higher Education Transformation [50]. While many programs have been put in place to address these dropout and throughput challenges, it continues to plague the South African higher education system. Drawing on Tinto's [51,52] student integration model as a key driver to retain students, much has been done in terms of the academic integration of students within universities, with extensive academic support processes put in place. With respect to Tinto's social integration aspect of student integration within universities, belonging to the institution has largely been conceptualized through institutional engagement and responds to the question of what institutions are doing to engage students socially to enhance their retention in their respective institution. The limitation of this perspective on retention is that it emerges from the institutional perspective. The gaze now needs to shift to students perspective and should ask how students would like to enhance their social integration into their respective institution. Hence, the notion of belonging that emerges from the students' perspective, which intrinsically would matter to the student, would open up spaces to explore, as in this study, a sustainable way of keeping students interested in their study programs, even in contexts such as COVID-19, where institutional isolation may have limited impact on students wanting to complete their qualifications and seek appropriate job prospects.

Noting that the majority of students enrolled were first generation students, their exposure to university education is relatively low. It is further noted that through an analysis of the depth of literature, student engagement continues to be a variable in educational research that is aimed at understanding, explaining and predicting student behaviour, emotional and cognitive elements in learning environments [49]. These two facts, viz., first generation higher education students and student engagement as a key variable in understanding student behaviour, emotional and cognitive elements, within higher education studies opens up a space for deeper insights into how belonging from the perspective of students may influence institutional responses to providing sustainable learning environments to retain students to completion within a transforming and disruptive context. First generation students have a deep sense of belonging to their respective communities and way of life. Their migration into an unfamiliar community would need extra sensitivity in relation to belonging to new communities (of practices), and as such, sensitivities to bridging cultural practices, meanings, symbols and values are key to student perceived successes [49], extending the notion of belonging in a familiar space to new spaces of being-behaviourally, emotionally and cognitively.

\section{Conclusions}

In conclusion, we return to SDGs 3 and 4 which focus on health and well-being as well as quality education, respectively. The COVID-19 pandemic brought issues of health and well-being into strong focus, and this includes the health and well-being of university students. The challenges that hard lockdowns brought about, including the pivot to online learning, have raised questions about the quality of education and how this could be provided to all students. With respect to university education, the two SDGs intersect because student health and well-being will inevitably impact on the quality of education. 
This study focused on how students perceived the pandemic to have affected their wellbeing, in particular, how the support provided by university lecturers and administration impacts on their levels of well-being, degree completion and job prospects. A key finding was that even though supporting students is important, increased support will not be effective unless students' sense of belonging is enhanced. Belonging was found to have a moderating effect in the relationship between the COVID-19 pandemic and well-being.

The study suggests that universities may need to give greater attention to students' sense of belonging when supporting them during the COVID-19 pandemic and beyond. The managerial implications of this study are important as they draw attention to a managerial reorientation. How might institutions focus efforts on the enhancement of the affective dimension of student experience, especially given that a student's sense of belonging and well-being ultimately contribute to student success/throughput? It might require that policy on student welfare be reviewed to foreground this aspect. There may be multiple reasons for the key finding of this study, and therefore, further qualitative studies need be conducted to corroborate this key finding so that stronger claims could be made. In South Africa, the value of $u b u n t u$, which is embraced by many, could serve as the ethical anchor for cultivating a greater sense of belonging in students. Universities should recognise that belonging is a dynamic process and that in a rapidly changing world, students' needs for belonging and their sense of belonging change and so, too, should universities' responses. Participation is an important ingredient for cultivating belonging, and students should be enabled to participate in as many domains of university life, including teaching/learning, research and community engagement. This is significant as it implies that students' sense of belonging is an integral part of well-being.

The COVID-19 pandemic has reminded us that life's journey is a bumpy road, that there are also cul-de-sacs, traffic circles, detours-sometimes, it requires us to reroute and even make a U-turn. Whether or not the targets for the SDGs are reached by 2030 is not important, rather, the commitment to what those SDGs embody is important. As human consciousness on issues of sustainability increases, the responsibility of the university to address issues of sustainability in all the activities also increases. In 2021, we saw the Times Higher Education introduce its impact rankings for the first time, which are the only global performance tables which assess universities against the United Nation's Sustainable Development Goals. Universities will have to increasingly account for their contributions towards both ecological sustainability and social justice. With respect to universities committing to what SDGs 3 and 4 embody, this study suggests that cultivating students' sense of belonging may be crucial.

Author Contributions: Conceptualization, all authors; formal analysis, G.P., A.V. and S.B.; data collection, S.B.; data curation, G.P. and S.B.; writing — original draft preparation, all authors; writingreviewing and editing, all authors; technical editing, S.B. and A.V.; visualization and supervision, all authors. The specific contributions of the authors were as follows: L.L.G. wrote the introduction; S.M. and S.S. wrote previous research and the hypothesis development; G.P., A.V. and S.B. wrote the method and results. The discussion and conclusion were chiefly written by L.R. and L.L.G. after a whole-team deliberation of key ideas. All authors have read and agreed to the published version of the manuscript.

Funding: This research received no external funding.

Institutional Review Board Statement: The study was conducted according to the guidelines of the Declaration of Helsinki, and approved by the Ethics Committee of Nelson Mandela University (H20-EDU-ERE-024) and approved on 20 May 2020.

Informed Consent Statement: Informed consent was obtained from all participants involved in the study.

Data Availability Statement: The datasets generated for this study are available on request to the corresponding author. 
Acknowledgments: This article builds on the design and conceptualization of a larger international project led by Gary Pheiffer.

Conflicts of Interest: The authors declare no conflict of interest.

\section{References}

1. United Nations Sustainable Development. Available online: https://sdgs.un.org/goals (accessed on 1 November 2020).

2. Haynes, N.; Cooper, L.A.; Albert, M.A. At the Heart of the Matter: Unmasking and Addressing the Toll of COVID-19 on Diverse Populations. Circulation 2020, 142, 105-107. [CrossRef] [PubMed]

3. Jean-Louis, G.; Turner, A.D.; Jin, P.; Liu, M.; Boutin-Foster, C.; McFarlane, S.I.; Seixas, A. Increased Metabolic Burden among Blacks: A Putative Mechanism for Disparate COVID-19 Outcomes. Diabetes Metab. Syndr. Obes. 2020, 13, 3471-3479. [CrossRef]

4. Harris, B.; Goudge, J.; Ataguba, J.E.; McIntyre, D.; Nxumalo, N.; Jikwana, S.; Chersich, M. Inequities in Access to Health Care in South Africa. J. Public Health Policy 2020, 32, S102-S123. [CrossRef] [PubMed]

5. Mhlanga, D.; Garidzirai, R. The Influence of Racial Differences in the Demand for Healthcare in South Africa: A Case of Public Healthcare. Int. J. Environ. Res. Public Health 2020, 17, 5043. [CrossRef]

6. Kecojevic, A.; Basch, C.H.; Sullivan, M.; Davi, N.K. The Impact of the COVID-19 Epidemic on Mental Health of Undergraduate Students in New Jersey, Cross-Section Study. PLoS ONE 2020, 15, e0239696. [CrossRef]

7. Sahu, P. Closure of Universities Sue to Coronavirus Disease 2019 (COVID-19): Impact on Education and Mental Health of Students and Academic Staff. Cureus 2020, 12, e7541. [CrossRef] [PubMed]

8. Cleophas, F.; Le Grange, L. A Critique of Neoliberalism in Sport: Towards Optimistic Sport in the Wake of the COVID-19 Pandemic. In From High-Risks Sports to Sports as High Risk: Crisis, Captulation and Creativity during COVID-19; Manik, S., Ed.; Alternation African Scholarship Book Series; CSSALL Publishers: Pietermaritzburg, South Africa, 2020; Volume 5, pp. $216-233$.

9. Power, K. The COVID-19 Pandemic Has Increased the Care Burden of Women And Families. Sus. Sci. Pract. Policy 2020, 16, 67-73. [CrossRef]

10. Alon, T.M.; Doepke, M.; Olmstead-Rumsey, J.; Tertilt, M. The Impact of COVID 19 on Gender Equality; National Bureau of Economic Research Working Paper Series; National Bureau of Economic Research: Cambridge, MA, USA, 2020. [CrossRef]

11. Miller, L. Belonging to Country-A Philosophical Anthropology. J. Aus. Stud. 2003, 27, 215-223. [CrossRef]

12. Du Preez, P.; Le Grange, L. The COVID-19 Pandemic, Online Teaching/Learning, the Digital Divide and Epistemological Access. In Re-Thinking the Humanities Curriculum within the Time of COVID-19; Ramrathan, L., Smit, J.A., Hlongwe, N., Mkhize, N., Eds.; Alternation African Scholarship Book Series; CSSALL Publishers: Pietermaritzburg, South Africa, 2020; Volume 1, pp. 90-106.

13. Plakhotnik, M.S.; Volkova, N.V.; Jiang, C.; Yahiaoui, D.; Pheiffer, G.; McKay, K.; Newman, S.; Reißig-Thust, S. The Perceived Impact of COVID-19 on Student Well-Being and the Mediating Role of the University Support: Evidence from France, Germany, Russia and the UK. Front. Psychol. 2021, 12, 2663. [CrossRef]

14. Lambert, L.; Passmore, H.A.; Holder, M.D. Foundational Frameworks of Positive Psychology: Mapping Well-Being Orientations. Can. Psych. 2015, 56, 311-321. [CrossRef]

15. Van de Velde, S.; Buffel, V.; Bracke, P.; Van Hal, G.; Somogyi, N.M.; Willems, B.; Wouters, E. The COVID-19 International Student Well-being Study. Scand. J. Pub. Health 2021, 49, 114-122. [CrossRef]

16. National Academies of Sciences and Medicine. Mental Health, Substance Use, and Wellbeing in Higher Education: Supporting the Whole Student; National Academies Press: Washington, DC, USA, 2021.

17. Aristovnik, A.; Keržič, D.; Ravšelj, D.; Tomaževič, N.; Umek, L. Impacts of the COVID-19 Pandemic on Life of Higher Education Students: A Global Perspective. Sustainability 2020, 12, 8348. [CrossRef]

18. Social Impact of the COVID-19 Pandemic on Youth in the Post School Education and Training (PSET) Sector in South Africa. Available online: https:/ / www.dhet.gov.za/SiteAssets/Media\%20Advisory\%20and\%20Statements\%202021/PSET\%20Youth\% 20survey\%20presentation_April\%202021.pdf (accessed on 7 October 2021).

19. COVID-19: Survey Finds 65\% of Students Reported Psychological Distress in 2020. Available online: https://www. dailymaverick.co.za/article/2021-06-14-covid-19-survey-finds-65-of-students-reported-psychological-distress-in-2020/ (accessed on 4 October 2021).

20. Soudien, C. Complexities of Difference and Their Significance for Managing Inequality in Learning: Lessons from the COVID-19 Crisis. Prospects 2020, 49, 59-67. [CrossRef] [PubMed]

21. Heymann, L.; Carolissen, R. The Concept of First-Generation Students in the Literature: Implications for South African Higher Education. S. Afr. J. High. Educ. 2011, 25, 1378-1396.

22. Duncan, N.; Strevens, C.; Field, R. Resilience and Student Wellbeing in Higher Education. Eur. J. Leg. Educ. 2020, 1, 83-115.

23. Baik, C.; Larcombe, W.; Brooker, A. How Universities Can Enhance Student Mental: The Student Perspective. High. Educ. Res. Dev. 2019, 38, 674-687. [CrossRef]

24. SA's Jobless Number Grows to 7.2 Million as Unemployment Rate Breaches New Record. Available online: https:/ /www.news2 4.com/fin24/economy/sas-jobless-grows-to-72-million-as-unemployment-rate-breaches-new-record-20210223 (accessed on 4 October 2021).

25. Mncayi, P.; Shuping, K. Factors Affecting Labour Absorption in South Africa. J. Econ. Fin. Sci. 2021, 14, 10. [CrossRef]

26. The Budget 2021: Slashing Public Expenditure Places the Economy at Risk. Available online: https://www.iej.org.za/the-budget2021-slashing-public-expenditure-places-the-economy-at-risk/ (accessed on 4 October 2021). 
27. Ye, Z.; Yang, X.; Zeng, C.; Wang, Y.; Shen, Z.; Li, X.; Lin, D. Resilience, Social Support, and Coping as Mediators between COVID-19-related Stressful Experiences and Acute Stress Disorder among College Students in China. Appl. Psych. Health Wb. 2020, 12, 1074-1094. [CrossRef]

28. Daddow, A.; Cronshaw, D.; Daddow, N.; Sandy, R. Hopeful Cross-Cultural Encounters to Support Student Well-Being and Graduate Attributes in Higher Education. J. Stud. Inter. Educ. 2020, 24, 474-490. [CrossRef]

29. Kareem, O.A.; Bing, K.W. Exploring Management Interventions in a Higher Education Institution for the Improvement of Student Well-Being. South Asian J. Bus. Manag. Cases 2014, 3, 101-107. [CrossRef]

30. Henning, M.A.; Krägeloh, C.U.; Dryer, R.; Moir, F.; Billington, R.; Hill, A.G. Wellbeing in Higher Education: Cultivating a Healthy Lifestyle among Faculty and Students; Routledge: London, UK, 2018.

31. Crawford, N.; Kift, S.; Jarvis, L. Supporting Student Mental Wellbeing in Enabling Education: Transitioning Students in Higher Education: Philosophy, Pedagogy and Practice; Routledge: London, UK, 2019.

32. Jones, E.; Priestley, M.; Brewster, L.; Wilbraham, S.J.; Hughes, G.; Spanner, L. Student Wellbeing and Assessment in Higher Education: The Balancing Act. Assess. Eval. High. Educ. 2020, 46, 438-450. [CrossRef]

33. Scobie, H.; Picard, M. Embedding Mental Wellbeing in Australian Regional Universities: Equity Interventions. Inter. Stud. Wide. Particip. 2018, 5, 65-79.

34. Khene, C.P. Supporting a Humanizing Pedagogy in the Supervision Relationship and Process: A Reflection in a Developing Country. Int. J. Dr. Stud. 2014, 9, 73-83. [CrossRef]

35. Eloff, I.; Graham, M. Measuring Mental Health and Well-Being of South African Undergraduate Students. Glob. Ment. Health 2020, 7, 1-10. [CrossRef] [PubMed]

36. Soudien, C.; Harvey, J. Trouble in Our Consensus about Learning: The Politics of Learning in the Contemporary Period. Pedagog. Cult. Soc. 2021, 29, 247-261. [CrossRef]

37. Lave, J.; Wenger, E. Situated Learning: Legitimate Peripheral Participation; Cambridge University Press: New York, NY, USA, 1991.

38. Wenger, E. Communities of Practice: Learning, Meaning, and Identity; Cambridge University Press: New York, NY, USA, 1999.

39. Godinic, D.; Obrenovic, B.; Khudaykulov, A. Effects of Economic Uncertainty on Mental Health in the COVID-19 Pandemic Context: Social Identity Disturbance, Job Uncertainty and Psychological Well-Being Model. Int. J. Innov. Econ. Dev. 2020, 6, 61-74. [CrossRef]

40. Hogg, M.A. Social Identity Theory. In Contemporary Social Psychological Theories, 2nd ed.; Peter, J., Ed.; Stanford University Press: Redwood City, CA, USA, 2018; pp. 112-138. [CrossRef]

41. James, N.; Thériault, V. Adult Education in Times of the COVID-19 Pandemic: Inequalities, Changes, and Resilience. Stud. Educ. Adults 2020, 52, 129-133. [CrossRef]

42. Mooney, C.; Becker, B.A. Investigating the Impact of the COVID-19 Pandemic on Computing Students' Sense of Belonging. In Proceedings of the 52nd ACM Technical Symposium on Computer Science Education (SIGCSE '21); Association for Computing Machinery: New York, NY, USA, 2021; pp. 612-618. [CrossRef]

43. Pierce, G.R.; Sarason, I.G.; Sarason, B.R. General and relationship-based perceptions of social support: Are two constructs better than one? J. Personal. Soc. Psychol. 1991, 61, 1028. [CrossRef]

44. World Health Organization. Wellbeing Measures in Primary Health Care/The Depcare Project: Report on a WHO Meeting; WHO Regional Office for Europe: Stockholm, Sweden, 1998.

45. Postmes, T.; Haslam, S.A.; Jans, L. A Single-Item Measure of Social Identification: Reliability, Validity, and Utility. Br. J. Soc. Psychol. 2013, 52, 597-617. [CrossRef]

46. IBM Corp. Released 2020. IBM SPSS Statistics for Windows, Version 27.0. IBM Corp.: Armonk, NY, USA. Available online: https:/ / www.ibm.com/support/pages/how-cite-ibm-spss-statistics-or-earlier-versions-spss (accessed on 10 November 2021).

47. Hayes, A.F. Introduction to Mediation, Moderation, and Conditional Process Analysis: A Regression-Based Approach, 2nd ed.; Guilford Publications: New York, NY, USA, 2017.

48. Yuval-Davis, N. Power, Intersectionality and the Politics of Belonging. In The Palgrave Handbook of Gender and Development; FREIA Working Paper Series No. 75; Harcourt, W., Ed.; Springer: Berlin/Heidelberg, Germany, 2016; pp. 367-381. [CrossRef]

49. Mkhize, J.S.; Ramrathan, L. Cultural Signals in Understanding First-Year Student Engagement: How Can Universities Become More Culturally Sensitive? The Case of a Rural South African University. S. Afr. J. High. Educ. 2021, 35, 107-125. [CrossRef]

50. Department of Education (DOE). Education White Paper 3: A Programme for the Transformation of Higher Education, (Notice 1196 of 1997). Gov. Gaz. 1997, 18207, 3-55.

51. Tinto, V. Dropout from Higher Education: A Theoretical Synthesis of Recent Research. Rev. Educ. Res. 1997, 45, 89-125. [CrossRef]

52. Tinto, V. Research and Practice of Student Retention: What Next? J. Coll. Stud. Retent. Res. Theory Pract. 2006, 8, 1-19. [CrossRef] 